\title{
Contribuições das Histórias em Quadrinhos para abordar questões ambientais na educação básica
}

\section{Contributions of Comics to address environmental issues in basic education}

\author{
${ }^{1}$ Barbara Doukay Campanini bcampanini@gmail.com \\ ${ }^{2}$ Marcelo Borges Rocha
}

\section{RESUMO}

O presente estudo refere-se à construção do conhecimento de forma coletiva a partir da elaboração de material didático através das histórias em quadrinhos. Por se tratar de um veículo de massa com fácil entendimento, seu conteúdo pode ser trabalhado em diferentes seguimentos contextualizando temas, tais como meio ambiente, nas aulas de ciências através de uma linguagem que une o texto à imagemproporcionandoao professor levar o aluno a refletir sobre questões que possam estar associadas ao seu cotidiano. As atividades seguiram uma sequência didática estruturada que envolveu pesquisa sobre questões ambientais, debate acerca da opinião dos alunos em relação as informações que obtiveram em suas pesquisas, dicas de como criar histórias em quadrinhos, a elaboração dos quadrinhos e discussões relacionadas à leitura dessas hitórias produzidas pelos alunos. Desta forma o conhecimento construído coletivamenteatravés das atividades contribuiu para o desenvolvimentoda argumentação dos alunos, a crítica de forma reflexiva, o hábito de leiturae para a organização do trabalho em equipe.

Palavras chave: Ensino de Ciências, Educação Ambiental, Histórias em Quadrinhos.

\begin{abstract}
This study refers to the construction of knowledge collectively from the development of teaching materials through the comics. Because it is a mass vehicle with easy to understand, its contents can be worked in different segments contextualizing subjects such as environment, in science classes through a language that unites the text in the image providing the teacher lead the student to reflect on issues that may be associated with their daily lives. The activities followed a structured instructional sequence that involved research on environmental issues, discussion about students' opinions regarding the information obtained in their research, tips for creating comics, the development of comics and discussions related to reading those produced hitórias by students. Thus the knowledge collectively constructed through the activities contributed to the development of the argument of the students, the critical reflectively, reading habits and the organization of teamwork.
\end{abstract}

Keywords: Science Education, Environmental Education, Comics.

1 Discente do Programa de Pós-Graduação em Ciência, Tecnologia e Educação - CEFET/RJ

2 Docente do Programa de Pós-Graduação em Ciência, Tecnologia e Educação - CEFET/RJ. 


\section{INTRODUÇÃO}

A leitura de histórias em quadrinhos pode levar os alunos a ampliarem seus conceitos possibilitando mais um caminho de compreensão e acesso às relações de comunicação entre sujeito e sociedade (KAMEL; LA ROCQUE, 2006).

Vale destacar que as histórias em quadrinhos possuem a função não só de entretenimento e hábito de leitura, elas também proporcionam aos professores a possibilidade de sensibilizar os alunos para o tema a ser discutido em sala de aula de maneira interdisciplinar levando em conta aspectos como o texto, a linguagem, os elementos naturais da paisagem, a caraterização, o tema abordado, expressão e o posicionamento dos personagens (CAMPANINI, 2016).

A aprendizagem por meio do imaginário possibilita o desenvolvimento da criatividade, habilidades e saberes através da leitura e elaboração das histórias que ilustram seus pensamentos, além de permitir a criança o enriquecimento do vocabulário e o prazer pela leitura.

Shulman (1987) destaca que o conhecimento docente se apoia em um tripé que se caracteriza através do conhecimento que se transforma em um objeto de ensino o qual viabilize o ensino do currículo. Para Zabala (1998, p. 20), "as sequências de atividades de ensino/aprendizagem, ou sequências didáticas, são uma maneira de encadear e articular as diferentes atividades ao longo de uma unidade didática”.

Sendo assim, os tipos de atividades propostas e a maneira como elas se articulam à dinâmica em grupo e aos tipos de relações que se estabelecem entre professor e aluno diferenciam a proposta didática determinando uma prática educativa diferenciada.

Diante do exposto esta pesquisa teve o objetivo deanalisar as contribuições do uso das histórias em quadrinhos no ensino de ciências como recurso didático para abordar temas ambientais.

\section{DESENHO METODOLÓGICO}

Este estudo foi realizado de forma exploratória e contextual o qual foram necessárias definições de estratégias a serem desenvolvidas e o aprofundamento do tema abordado, assim como a discussão, reflexão, avaliação da metodologia aplicadae a confecção do material, através da pesquisa participativa em que os próprios sujeitos envolvidos participaram da construção do conhecimento através da troca de experiências e informações (LE BOTERF, 1984; BORDA, 1999).

A seguir serão descritas de forma sucinta as etapas do desenvolvimento das atividades propostas para os participantes deste estudo e posterior análise dos resultados da entrevista coletiva a qual abordamos a opinião dos alunos após a oficina de histórias em quadrinhos.

As atividades realizadas na oficina foram compostas por em seis encontros uma vez por semana após o horário das aulas e cada encontro teve a duração de 45 minutos. Contamos com a participação voluntária de 12 alunos do $9^{\circ}$ ano do Ensino Fundamental de uma escola particular na Zona Norte da cidade do Rio de Janeiro.

Ao final das atividades os alunos participaram de uma entrevista para que pudessem avaliar se houve influência do trabalho realizado na oficina de histórias em quadrinhos sobre os conceitos de meio ambiente e preservação. Além disso, foi investigado o hábito de leitura, o interesse pelas aulas de ciências, a compreensão dos temas abordados e suas impressões positivas e/ou negativas sobre o trabalho realizado. 
Dessa forma, ao concluir todas as etapas da oficina foi possível analisar os resultados dos materiais produzidos pelos os alunos discutindo-se as respostas obtidas na entrevista e verificando a percepção deles acerca da utilização das histórias em quadrinhos em sala de aula. Nesse sentido, acreditamos que através da proposta de inserção das histórias em quadrinhos no contexto escolar para trabalhar questões ambientais, possamos contribuir de forma positiva com o Ensino de Ciências.

\section{1 Oficina de Histórias em Quadrinhos}

Para compor as atividades da oficina os alunos realizaram pesquisas em diferentes tipos de mídias sobre meio ambiente e problemas ambientais para serem discutidas no debate. Os principais temas que iriam compor as histórias foram escolhidos de forma coletiva. O desenvolvimento e a elaboração pontuaram os seguintes assuntos: escassez, poluição (rios e mares), descarte inadequado de materiais, reciclagem e redução de desperdício.

O debate foi mediado pela pesquisadora que complementou os aspectos que estavam sendo discutidos com algumas provocativas para que os alunos fossem levados a uma crítica reflexiva. Os alunos foram estimulados a expor seus pontos de vista em relação à leitura realizada nas pesquisas, trazendo dúvidas e até mesmo refletindo acerca de possíveis soluções e/ou contribuições relativos aos problemas levantados. Esse momento possibilitou observar a interação entre os alunos, a troca de experiências e, principalmente, perceber que eles foram identificando a aproximação do conteúdo trabalhado às questões ambientais do seu cotidiano.

Para a elaboração das histórias em quadrinhos foi apresentado ao grupo o vídeo de Mauricio de Souza que apresenta algumas propostas de desenho e elaboração de histórias em quadrinhos. A cada encontro os alunos recebiam mais informações sobre o processo de elaboração dos quadrinhos e discutiam quais seriam as questões mais importantes para serem abordadas. Um assunto escolhido e muito destacado na mídia foi a poluição da Baia de Guanabara. Contudo, outra grande preocupação discutida foi a falta d’água e o consumo desenfreado deste recurso.

Os alunos também se apropriaram de modelos de passo a passo de como criar histórias em quadrinhos de maneira simples e objetiva. O roteiro abordava cinco etapas básicas, tais como: pensar nas cenas que se passaria a história imaginando os aspectos físicos do local, a criação do roteiro planejando quadro a quadro de forma seria aboradada o tema escolhido, a criação dos personagens (aspectos físicos e psicológicos), a elaboração de recursos (balão de fala e acriação de sons e pensamentos) e a delimitação dos planos de cada quadro (plano médio, close, foco, etc.).

Após essas dicas e instruções os alunos tiveram acesso a histórias em quadrinhos da "Turma da Mônica" de Maurício de Souza e da "Turma do Xaxado" de Antônio Cedraz - que trata de temas ambientais de forma reflexiva. Dessa forma eles puderam identificar todas as etapas da criação dos quadrinhos e a partir desse momento começaram a elaborar os roteiros para a construção das HQs.

Após a construção dos quadrinhos, os alunos participaram de uma roda de leitura para que apresentassem suas histórias e trocassem experiências discutindo sobre o que os motivou a escrevê-las e de que forma essa atividade contribuiu para a construção do conhecimento e a elaboração dos saberes desenvolvidos de forma coletiva.

A presente pesquisa atente as exigências do Comitê de Ética segundo parecer emitido sob o núemro 565/10.

\section{RESULTADOS E DISCUSSÃO}

As imagens abaixo ilustram uma parte das histórias produzidas pelos alunos. Observa-se que a pesquisa realizada apontou para a discussão da mídia em relação aos problemas ambientais como a poluição e escassez 
da água, descarte inadequado de esgoto, refletindo também a preocupação com as olímpíadas, como mostram as figuras $1 \mathrm{e} 2$.

Figura 1 - Relação entre a Baia de Guanabara com a poluição e os dias atuais.

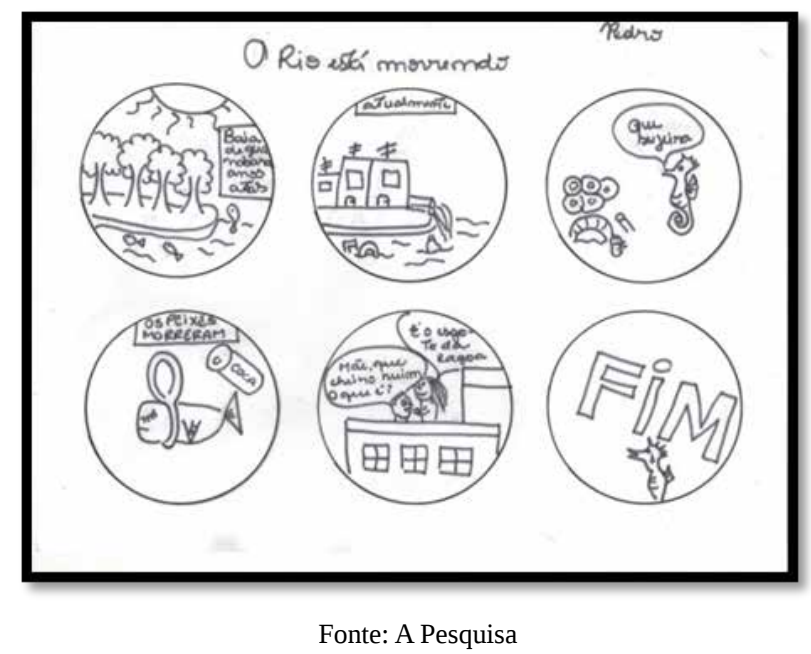

Figura 2 - Representa o desperdício de águademosntrando possível escassez.

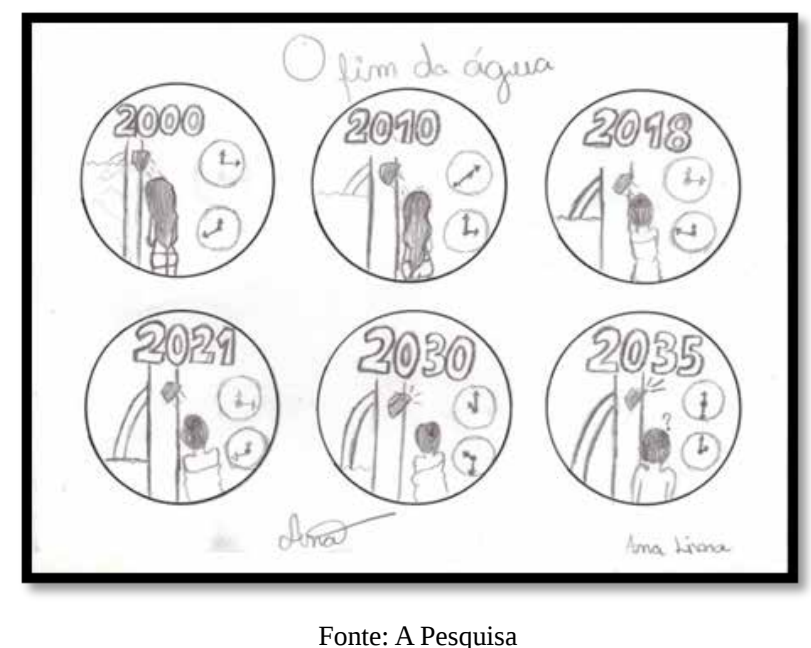

Com o intuito de analisar a contribuição das atividades oferecidas na oficina procuramos identificar através da realização da entrevista a opinião dos alunos quanto à produção dos quadrinhos e todo seu processo de construção. Para preservar a identidade dos alunos utilizamos em suas falas a representação por letras de A-Z.

As questões para a entrevista seguiram algumas considerações como: O uso das histórias em quadrinhos nas aulas de ciências poderia despertar mais interesse por parte dos alunos pelo hábito de leitura? Os alunos consideraram que o uso das histórias em quadrinhos em sala de aula desperta mais o interesse pelas aulas por apresentar as imagens associadas ao conteúdo que está sendo discutido. Em argumentação um aluno disse que:

“isso desperta a nossa imaginação. A atenção vai e volta do texto para imagem e a aula fica dinâmica” (aluno A).

Outra questão abordada foi se a leitura das histórias em quadrinhos, criadas pelos colegas e discutidas durante a oficina, possibilitou entender melhor o contexto das aulas. Eles consideraram que leitura e a discussão das 
histórias em quadrinhos criadas pelos próprios colegas geraram uma aproximação pela atividade de elaboração do material. E para criar essas histórias foi preciso ler em diferentes mídias, pesquisar sobre o assunto antes da aula, debater e trabalhar em equipe para elaborar o material. Um aluno destacou que:

"a aula fica mais divertida, mas fácil de entender e todos estão juntos falando do mesmo assunto. Dificilmente vamos ter conversas paralelas porque todos querem participar, contar suas experiências e dar opinião” (aluno B).

Procuramos saber, na opinião dos alunos, se as aulas de ciências sendo construídas de forma coletiva despertariam mais interesse pelo conteúdo didático. Eles disseram que as aulas de ciências sob essa perspectiva fazem com que o aluno leia sobre o tema que será discutido e se sinta estimulado visto que eles acabam competindo de uma forma saudável para ver que tem mais argumentos para discutir no debate. Cabe ressaltar que a mediação do professor é muito importante para conduzir o debate e esclarecer as dúvidas que vão surgindo conforme os diferentes pontos de vista. Um aluno acresecentou que: “para discutir você precisa de argumentos, então, acaba pesquisando e estudando sem perceber. E o
melhor, sem decorar” (aluno C).

Perguntamos também se eles consideravam importante discutir sobre temas relacionados a questões ambientais nas aulas de ciências. Ao discutirem sobre os temas relacionados a problemas ambientais nas aulas de ciências abordando principalmente as consequências das nossas atitudes como sociedade em geral, os alunos relataram que isso favorece a reflexão de forma crítica mencionando que:

"nós aprendemos sobre as plantas nas aulas de ciências, mas não sobre a importância delas no meio ambiente. Discutir sobre as consequências da falta delas, por exemplo, é muito importante porque leva a uma reflexão sobre as nossas próprias atitudes” (aluno D).

A última questão pretendeu verificar quais aspectos positivos e/ou negativos poderiam ser considerados para esta oficina de HQs. Os alunos colocaram que o tempo foi um fator negativo. Por ser extracurricular, a pesquisa foi realizada fora do horário de aula. Eles consideraram que se houvesse mais aulas poderiam ter aprendido mais. Alguns colegas da turma também disseram que se fosse no horário de aula gostariam de participar da oficina. No entanto, para os alunos que puderam participar da pesquisa, esses momentos foram considerados diferentes, importantes, divertidos e atrativos para tratar de questões ambientais nas aulas de ciências. Todos os momentos foram muito interativos, aproximaram os colegas e geraram discussões que em uma aula tradicional possivelmente não ocorreria. Dois alunos consideraram que:

"foi uma forma muito criativa de aprender e conscientizar os alunos da importância do meio ambiente e percebendo que somos um só” (aluno C)

“aprender sobre a importância do meio ambiente no nosso dia a dia faz com que tenha mais significado estudar porque estamos entendendo também qual a nossa relação com o planeta” (aluno F).

Durante a realização da oficina percebemos que a prática utilizada aproximou as discussões à interpretação dos textos de forma que os alunos puderam experimentar o conteúdo abordado vinculando a vivência do seu cotidiano. Ao trabalhar temas ambientais de maneiraprazerosa, as aulas tornaram-se mais dinâmicas, interessantes e divertidas, fazendo com que se sentissem motivados às atividades de leitura ampliando o a compreensão do aluno sobre a importância do meio ambiente.

As histórias em quadrinhos possuem elementos altamentes significativos para o processo de socialização de valores e elementos culturais. Braga (2009) destaca que os quadrinhos possuem um grande potencial para educação e exercício de cidadania através de suas histórias. Em sua pesquisa, o autor descreve a produção de 
recursos didáticos em ciências sociais e sua utilização pelos professores com o intuito de verificar a eficiência deste tipo de produção de material para o ensino, identificando, dessa forma, a possibilidade do uso da produção de histórias em quadrinhos para trabalhar as necessidades culturais e pegagógicas. Sendo assim, não apenas como entrenimento, porém, com cunho pedagógico e artístico trabalhado de forma adequada através das histórias, torna-se possível promover junto aos alunos, por exemplo, o exercício da cidadania, aproximando-o de sua memória histórica e cultural.

A ideia de se trabalhar a produção de histórias em quadrinhos em sala de aula é de proporcionar aos alunos o interesse pela pesquisa, despertar o hábito de leitura e o desenvolvimento de estratégias para elaboração de temas que naveguem pela imaginação sem deixar de lado a realidade e os obstáculos enfrentados no dia a dia. Embora saibamos que existam pessoas que possuam maior facilidade no processo de criação das histórias pretendemos mostrar que todos podem participar e colaborar com experiências próprias, assim como desenvolvimento do pensamento crítico.

Segundo Guimarães et al. (2013) todo artista criador de sua obra está construindo um mundo à parte. Partindo desse princípio, as histórias em quadrinhos possuem características específicas e autônomas que envolvem a criação de universos ficcionais. Os autores descrevem diversas obras clássicas de ficção que exploraram inúmeras possibilidades na linguagem dos quadrinhos como "Litte Nemo in Slumberland" de Winsor McCayque retrata a história de um menino que sonha todas as noites com um mundo onírico e acorda sempre caindo da cama, o lendário “Tintin” de Hergé, entre outros. Eles também chamam a atenção para o contexto direcionado a uma esfera teórica acerca das características das histórias em quadrinhos a fim de atingir um linear entorno dos elementos sociais como costumes, comportamentos, entre outros aspectos, para criação de possíveis vínculos com discussões sobre ética, tolerância e diversidade (GUIMARÃES et al., 2013).

Diante dessa perspectiva, procuramos analisar a opinião dos alunos quanto à utilização de histórias em quadrinhos para leitura e elaboração de novas histórias abordando questões ambientais como proposta para criação de um recurso didático complementar no Ensino de Ciências.

Verificamos respostas positivas em relação ao uso deste material nas aulas de ciências onde foi possível observar que todos os alunos consideraram que o uso das histórias quadrinhos torna a aula mais produtiva, atrai a atenção e desperta o interesse para o conteúdo escolar.

De acordo com estudo realizado por Kamel e La Rocque (2006), com o intuito de analisar a forma com que autores de livros didátidos utilizam tiras e histórias em quadrinhos, a utilização desses materiais contribui para a promoção de reflexões e torna-se um facilitador para a aprendizagem de forma significativa.

Desse modo, a leitura pode levar os alunos a ampliarem sua compreensão, possibilitando o acesso de comunicação entre sujeito e sociedade. Dessa forma, é sugerido o uso das histórias em quadrinhos como recurso complementar ao livro didátdico como forma de auxiliar o professor a analisar os conceitos aprendidos pelos alunos e como eles os relacionam as suas experiências. Ao fazer a relação com essas informações este processo torna-se fundamental para a ampliação da própria estutura cognitiva do aluno (KAMEL; LA ROCQUE, 2006).

Portanto, de acordo com Pizarro (2009), conclui-se que a utilização das histórias em quadrinhos é tão possível quanto fundamental desde que se apresentem dados nesses estudos que apontem a elaboração de metodologias que priorizem a reflexão da Ciência, assim como a visão de humor e entretenimento para os alunos. Com isso, o uso deste material em práticas pedagógicas torna-se um instrumento a mais para promover o interesse e motivar o aprendizado dos alunos de maneira lúdica e prazerosa. 


\section{4}

\section{CONCLUSÃO}

Este estudo envolveu atividades que despertaram nos alunos o interesse pela informação. A associação das questões ambientais ao seu cotidiano trouxe reflexões positivas acerca da proximidade da ciência e a tecnologia. Com o uso das histórias em quadrinhos foi possível interagir com o imaginário e os problemas socioambientais.

Portanto, ao considerarmos o apelo lúdico dos quadrinhos como importante recurso, verificando-se anecessecidadedouso de estratégias que aproximem o aluno e facilitem essa compreensão, torna-se possível diminuir a distância entre o conhecimento científico e os alunos, ampliando o olhar deles para as fontes de conhecimento.

Sendo assim, a presente pesquisa contribuiu no sentido de problematizar o desafio de inserir outros materiais que não só o livro didático no contexto escolar, dispondo de recursos que não possuem alto custo, podendo ainda ser confeccionado pelos próprios alunos e professores para tratar as questões ambientais no Ensino de Ciências.

\section{REFERÊNCIAS}

BORDA, O.F. Aspectos teóricos da pesquisa participante. In Pesquisa Participante. C. R. Brandão (Ed.), São Paulo: Brasiliense, 1999, pp. 42-62.

BRAGA, J. X. A. A produção de história em quadrinhos enquanto recurso didático no ensino das ciências sociais,

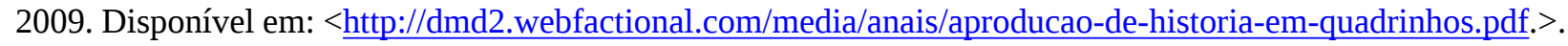
Acessado em: 01 maio 2016.

CAMPANINI, B. D. Análise da contribuição das histórias em quadrinhos na problematização de questões ambientais no ensino fundamental. 2016. 132f. Dissertação (Mestrado em Ciência, Tecnologia e Educação) - Programa de Pós-Graduação em Ciência, Tecnologia e Educação, Centro Federal de Educação Tecnológica Celso Suckow da Fonseca - CEFET, RJ, 2016.

GUIMARÃES, E.; FRANCO, E. S.; CHAVES, G. L.; ANDRAUS, G.; MAGALHÃES, H.; MOURA, M.; PELVINI, R. F. Hitórias em Quadrinhos e Práticas Educativas. O trabalho com universos ficcionais e fanzines. 1 ed. - São Paulo: Criativo, 2013.

KAMEL, L; LA ROCQUE, L DE. As histórias em quadrinhos como linguagem fomentadora de reflexões uma análise de coleções de livros didáticos de ciências naturais no ensino fundamental. Revista Brasileira de Pesquisa em Educação em Ciências, v. 6, n. 3, 2006.

LE BORTEF, G. Pesquisa participante: proposta e reflexões metodológicas. In: Repensando a Pesquisa Participante (C. R. Brandão, org.), São Paulo: Brasiliense, p. 51-81, 1984.

PIZARRO, M. V. As histórias em quadrinhos como linguagem e recurso didático no Ensino de Ciências. In: ENCONTRO NACIONAL DE PESQUISA EM ENSINO DE CIÊNCIAS, 7, 2009. São Paulo, Anais... São Paulo, 2009.

SHULMAN, L. S. Knowledge and teaching: foundations of a new reform. Educational Review Harvard, v. 57, n. 1, p. 1-22, 1987.

ZABALA, A. A prática educativa: como ensinar. Porto Alegre: Artes médicas, 1998. 